\title{
SOCIALIZATION OF ANALYSIS OF TOTAL TERPENOIDS FROM MANILTOA GRANDIFLORA (A. GRAY) SCHEFF LEAVES USING TLC METHODS
}

\author{
Jhon Patar Sinurat ${ }^{1 *}$, Reh Malem br Karo ${ }^{2}$, Rinaldo Berutu ${ }^{3}$ \\ ${ }^{1}$ Departement of Medical Laboratory Technology, Institut Kesehatan Medistra Lubuk Pakam \\ ${ }^{2}$ Departement of Pharmacy, Universitas Prima Indonesia \\ ${ }^{3}$ Departement of Pharmacy, Institut Kesehatan Medistra Lubuk Pakam \\ Sudirman street No. 38, Deli Serdang, North Sumatera, 20512. Indonesia \\ JIn. Sudirman No.38 Lubuk Pakam, Kabupaten Deli Serdang, \\ Sumatera Utara - Indonesia \\ *email korespondensi author: jhonpatar12@gmail.com
}

\section{DOI $10.35451 /$ jpk.v1i1.738}

\begin{abstract}
Saputangan leaves contained terpenoids which appeared reddish brown rings when tested using Liebermann Burchard, Salkowski and cerric sulfate. Saputangan leaves were macerated, then partitioned to obtain total terpenoids using a separatory funnel while checking filtrate partition with cerric sulfate. Extracts dissolved with methanol were partitioned with $n$-Hexane and then partitioned between aquadest and ethyl acetate in a ratio of 1: 1 to obtain $50 \mathrm{~g}$ of total terpenoids. TLC analysis was carried out on total terpenoids using n-hexane: acetone $(80: 20 \mathrm{v} / \mathrm{V})$ as the mobile phase and TLC plate with silica gel surface. The elution process was carried out in the chamber and the results of TLC were sprayed using Cerric Sulfate reagent. The total terpenoids were proved that terpenoids have 11 terpenoids as red stain based on their Rf. Based on the results of tests conducted on participants who were involved in socialization, it was stated that around $98 \%$ of participants had understood about terpenoid compounds, the extraction process of these compounds and how the elution process in TLC was. After socializing the material about these terpenoid compounds, the public increasingly understands that there are many chemical compounds that are beneficial to human health whose sources come from plants. These chemical compounds can be secondary or primary metabolites.
\end{abstract}

Keywords: Terpenoids, Maceration, Partition, TLC and Rf

\section{Introduction}

Terpenoids could act as important material in production of flavors, fragrances, high grade lubricants, biofuels, agricultural chemicals, and medicines. Most of the terpenoids are used for the treatment of many diseases. Terpenoids was main component in atsiri oil. Sesquiterpenoids are antifungals and insecticides. Additionally, $\beta$-terpene and $\beta$ terpinolene in Melaleuca alternifolia could contributed in antioxidant activity. Some terpenes are potent against heart disease, malaria, and cancer. (Rassem et al., 2016). Terpenes consist five carbon as isoprene units which are connected to each other by thousands of ways. Terpenoids are divided into monoterpenes, sesquiterpenes, diterpenes,sesterpenes, and triterpenes. (Perveen, 2018). Terpenes are simple hydrocarbons, with non-polar propeties generally. (Lingala \& Ghany, 2016)

Saputangan plants (Maniltoa grandiflora (A. Gray) Scheff) are plant that included to the genus Maniltoa and Fabaceae family that was mostly useful as medicinal. Parts used as medicine are leaves, flowers, root bark, and bark. 
Received: 14 June 2021 :: Accepted: 16 June 2021 :: Published: 30 June 2021

Saputangan leaves according to the screening test was positively contained Terpenoids. Saputangan plants are usually used as ornamental plants that can reduce pollution by absorbing pollutants such as carbon monoxide. (Scheff \& Sinurat, 2018)

Terpenoids can extract with maceration and partition. Maceration is immersing plants (in the form of powder) in a closed container with the solvent at room temperature, which is allowed to soak for a certain period with several times stirring. ( $\mathrm{Nn}, 2015)$. Partition is using two immiscible solvents in a separating funnel, and the compounds are distributed in two solvents according to their different partition coefficients. (Otsuka, 2016).

Analysis of total terpenoid is performed on thin Layer Chromatography (TLC). Thin layer chromatography can be used to separating the compounds present in a mixture and determining the purity of a substance. TLC is performed on an aluminum plate coated with a adsorbent material, usually silica gel, alumina or cellulose. (Namir et al., 2019)

This seminar aims to socialize and educate the member of seminar, so that understand that terpenoid compounds are secondary metabolites that are very beneficial for human health. The socialization of the saputangan plant was also explained in full starting from phytochemical screening to identify terpenoid compounds, extraction using maceration and partition methods in obtaining plant extracts and conducting TLC analysis to see the content of terpenoid compounds in saputangan.

\section{Methods}

This service activity is carried out through seminars using the lecture method, question and answer, and demonstrations. Identification of terpenoid compounds in Saputangan leaves was carried out through phytochemical screening. Extraction of saputangan leaves was carried out by maceration and partition methods. TLC analysis was carried out to analyze the terpenoid total in the sample. The procedure steps used in this service activity are as follows:

\section{Preparation stage}

Prepare socialization materials containing the equipment and materials used as well as media that support this activity. The samples used were saputangan leaves which were prepared in powder form.

Materials: Saputangan leaves powder, Ethanol, Methanol, Ethyl Acetate, nHexane, Acetone, Reagent of Cerric Sulfate, Reagent of Liebermann Burchard, Reagent of Salkowski and Aquadest. All the solvents and reagents used in this study as pro analysis and High grade.

Equipments: Macerator and Separatory Funnel Schoot Duran merck, Waterbath Memert merck, Rotary Evaporator Heidolph Merck, TLC plate was performed using silica gel $60 \mathrm{~F}_{254}$ (E.Merck) and Chamber.

\section{Implementation Stage}

Socialization regarding TLC analyses of Terpenoid was carried out directly to participants through seminar activities. This socialization is expected to open and broaden the participants knowledge. The leaf extract obtained by maceration with etanol and partition with ethyl acetate and n-hexane. The terpenoid reagents used were cerium sulfate, salkowski and liebermen Burchard. Thin layer chromatography analysis was carried out on dry extract using a stationary phase of Merck $60 \mathrm{~F}_{254}$ silica gel which was found on the surface of the TLC plate. Measure of TLC plat is $10 \times 2 \mathrm{~cm}$. The mobile phase was used $\mathrm{n}$-hexane : acetone with a ratio solvents varying 90:10, 80:20, 70:30 and $60: 40 \mathrm{v} / \mathrm{v}$.

\section{Evaluation and Follow-up}

Implementers of service activities evaluate the understanding of seminar participants through discussions and questions and answers regarding the results of TLC analysis of terpenoid compounds. Then carry out follow-up activities when participants are still not able to understand well. 
Received: 14 June 2021 :: Accepted: 16 June 2021 :: Published: 30 June 2021

\section{Result and Discussion Terpenoids screening}

The terpenoids in sample were analysed use Cerric Sulfat, Liebermann Burchard and Salkowski Reagents. The results in Figure 1 showed Maniltoa grandiflora contained terpenoids with the appearance of a reddish brown ring on the sample. (Malik et al., 2017)

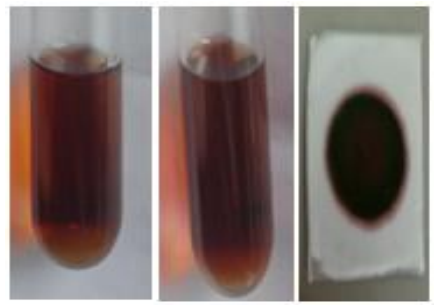

Figure 1. Terpenoid screening

\section{Maceration and Partition}

Macerate was filtered and evaporated using a rotary evaporator to obtain a solid extract of $350 \mathrm{~g}$. Partition was used $\mathrm{n}$-hexane and ethyl acetate which are carried out in stages so that the extract of the saputangan leaves is contained a total terpenoid as $50 \mathrm{~g}$.

\section{TLC Analyses of Total Terpenoid}

TLC analyses was performed with TLC using n-Hexane: Acetone (80:20 $\mathrm{v} / \mathrm{v}$ ) as elunet. After the elution, the TLC plate was sprayed with Cerric Sulfate reagent and heating due to all terpenoids and steroids (Ludwiczuk et al., 2017) will produce red stain. Stains were separated into 11 stains which had a different retention factor (Rf). There were Rf1 (0.27), Rf2 (0.36), Rf3 (0.47), Rf4 (0.61), Rf5 (0.68), Rf6 (0.85), Rf7 (0.87), Rf8 (0.88), Rf9 (0.90), Rf10 (0.93) dan Rf11 (0.98) which are shown in figure 2.

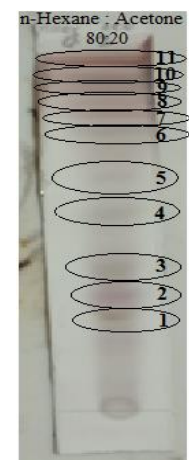

Figure 2. Total Terpenoid on TLC analyses
The results obtained from this service activity are as follows:

1. The seminar material can be understood by the seminar participants as evidenced by the result of pre-test and post-test showed $98 \%$ participants had understood.

2. Seminar participants gain new knowledge about the benefits of several ornamental plants that can be used as medicinal plants. Socialization showed in figure 3.

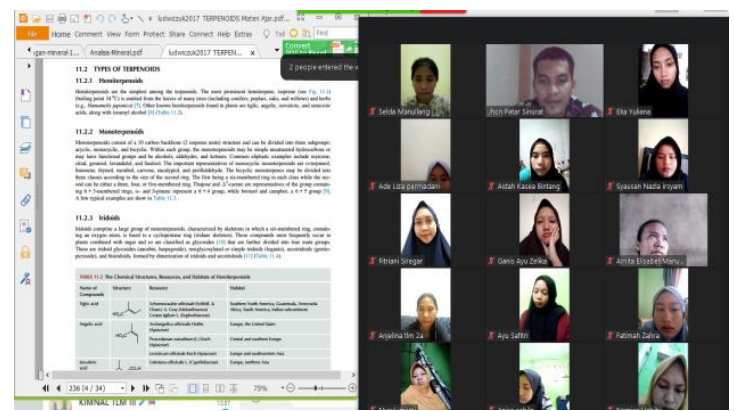

Figure 3. Socialization by application

\section{Conclusion}

Saputangan leaves contained terpenoids which appeared reddish brown rings when tested using Liebermann Burchard, Salkowski and cerric sulfate. Saputangan leaves were macerated, then partitioned to obtain total terpenoids using a separatory funnel while checking filtrate partition with cerric sulfate. The total terpenoids were analyzed with TLC Methods and proved that terpenoids have 11 terpenoids as red stain based on their Rf. Based on the results of tests conducted on participants involved in socialization, it was stated that around $98 \%$ of participants had understood terpenoid compounds.

\section{Acknowledgement}

Authors sincerely appreciate the financial and moral support from:

a. Direktorat Penelitian \& Pengabdian Masyarakat (DRPM), Kementrian Riset, Teknologi, \& Pendidikan Tinggi Republik Indonesia.

b. Institut Kesehatan Medistra Lubuk Pakam. 


\section{References}

Lingala, S. M., \& Ghany, M. G. M. Mhs. (2016). Extraction and Analysis of Terpenes/ Terpenoids Public Access. 25(3), 289-313. https://doi.org/10.1002/cppb.20024. Extraction

Ludwiczuk, A., Skalicka-Woźniak, K., \& Georgiev, M. I. (2017). Terpenoids. In Pharmacognosy: Fundamentals, Applications and Strategy. https://doi.org/10.1016/B978-0-12802104-0.00011-1

Malik, S. K., Ahmad, M., \& Khan, F. (2017). Qualitative and quantitative estimation of terpenoid contents in some important plants of Punjab, Pakistan. Pakistan Journal of Science, 69(2), 150-154.

Namir, H., Hadzic, R., Malesevic, I., Jurcevi, M., \& Starcevic, D. en. (2019). Application of thin layer chromatography for qualitative analysis of gunpowder in purpose of life prediction of ammunition. International Journal of Biosensors \& Bioelectronics, 5(1), 3-12.

Nn, A. (2015). A Review on the Extraction Methods Use in Medicinal Plants, Principle, Strength and Limitation. Medicinal \& Aromatic Plants, 04(03), 3-8. https://doi.org/10.4172/21670412.1000196

Otsuka, H. (2016). Purification by Solvent Extraction Using Partition Coefficient. Natural Products Isolation, 20, 269-273. https://doi.org/10.1385/1-59259955-9:269

Perveen, S. (2018). Introductory Chapter: Terpenes and Terpenoids. Terpenes and Terpenoids, 1-12. https://doi.org/10.5772/intechopen.7 $\underline{9683}$

Rassem, H., Nour, A., \& R. M., Y. (2016). Techniques For Extraction of Essential Oils From Plants: A Review. Australian Journal of Basic and Applied Sciences, 10(16), 117-127.

Scheff, A. G., \& Sinurat, J. P. (2018). Isolation of Phenolic Compound \& Antioxidant from Saputangan Leaves (Maniltoa Grandiflora). 5(4), 60-65 